\title{
The role of awareness in delay and trace fear conditioning in humans
}

\author{
DAVID C. KNIGHT, HANH T. NGUYEN, and PETER A. BANDETTINI \\ National Institute of Mental Health, Bethesda, Maryland
}

\begin{abstract}
Expression of conditional fear without awareness has been previously demonstrated during delay conditioning, a procedure in which the conditioned stimulus (CS) and unconditioned stimulus (UCS) overlap. However, less is known about the role of awareness in trace fear conditioning, where an interval of time separates the CS and UCS. The present study assessed skin conductance response (SCR) and UCS expectancy during delay and trace conditioning. UCS predictability was varied on a trial-bytrial basis by presenting perithreshold auditory CSs. Differential UCS expectancies were demonstrated only on perceived delay and trace trials. Learning-related SCRs were observed during both perceived and unperceived delay CSs. In contrast, differential SCRs were demonstrated only for perceived trace CSs. These data suggest that awareness is necessary for conditional responding during trace, but not delay, fear conditioning.
\end{abstract}

Cognitive and behavioral neuroscience research suggests that separate memory systems exist within the human brain that acquire and store distinct features of fearful experiences (Bechara et al., 1995; LeDoux, 2000; Milner, Squire, \& Kandel, 1998). One system is responsible for consciously recalled facts and details of events (declarative memory), whereas the other system mediates the expression of learned fear responses that occur without conscious thought (nondeclarative memory; Milner et al., 1998; Squire, 1992). These separate memory systems appear to be mediated by distinguishable, but partially overlapping, neural circuits (LeDoux, 2000; Milner et al., 1998). The degree to which these memory systems are independent and the conditions in which they interact are unresolved issues in the study of emotional learning and memory.

The laboratory study of fear learning and memory has traditionally used a Pavlovian conditioning paradigm, in which the presentation of a neutral stimulus (conditioned stimulus, CS) predicts an aversive event (unconditioned stimulus, UCS) such as electric shock or loud noise. Expression of a conditional response (CR) to the CS is taken as evidence that an association between the CS and UCS has been learned. CR expression during Pavlovian conditioning reflects a type of associative learning that is often classified as a nondeclarative memory. However, declarative memory (awareness) processes are also clearly engaged during standard conditioning tasks (Knight, Cheng,

This research was supported by the Intramural Research Program of the NIH. We thank Alex Martin for his helpful comments.Correspondence should be addressed to D. C. Knight, Section on Functional Imaging Methods, Laboratory of Brain and Cognition, National Institute of Mental Health, Building 10, Room 1D80, Bethesda, MD 20892 (e-mail: knightd@mail.nih.gov)
Smith, Stein, \& Helmstetter, 2004; Knight, Nguyen, \& Bandettini, 2003; Manns, Clark, \& Squire, 2000). Delay and trace conditioning are two Pavlovian learning procedures that differ in the temporal relationship between the CS and UCS. In delay conditioning, the CS and UCS overlap, whereas in trace conditioning, a temporal gap (i.e., the trace interval) separates CS termination and UCS onset. Studies of the classically conditioned eyeblink response suggest that the trace interval increases the complexity of the conditioning task and requires an awareness of the CS-UCS relationship for CR acquisition (Clark \& Squire, 1998; Manns et al., 2000). In contrast, awareness does not appear necessary for simple delay conditioning, because the CS and UCS overlap (Clark \& Squire, 1998; Gabrieli et al., 1995; Smith, Clark, Manns, $\&$ Squire, 2005). Furthermore, this line of research has demonstrated that awareness of stimulus relationships and $\mathrm{CR}$ acquisition develop concurrently during differential trace eyeblink conditioning (Manns et al., 2000), and that UCS expectancy influences CR expression during trace, but not delay, eyeblink procedures (Clark, Manns, $\&$ Squire, 2001). These studies indicate that an awareness of stimulus contingencies is necessary for CR acquisition during trace, but not delay, procedures (Clark et al., 2001; Clark \& Squire, 1998, 1999; Gabrieli et al., 1995; Manns et al., 2000; Smith et al., 2005). Similar observations of learning without awareness have been found during Pavlovian fear conditioning (Bechara et al., 1995; Esteves, Parra, Dimberg, \& Öhman, 1994; Knight et al., 2003). These studies suggest that contingency awareness does not influence differential CR expression during certain delay procedures (Knight et al., 2003), whereas awareness of stimulus relationships appears to facilitate trace fear conditioning and is correlated with $\mathrm{CR}$ expression during the extinction of trace conditioned fear (Carter, Hofstötter, Tsuchiya, \& Koch, 2003). 
In the present study, skin conductance response (SCR) and UCS expectancy (see Figure 1) were measured concurrently as participants were exposed to a differential delay or trace fear conditioning procedure (see Figure 2). During conditioning, one tone $(\mathrm{CS}+)$ predicted a loud white noise while a second tone $(\mathrm{CS}-$ ) was presented alone. UCS predictability was varied on a trial-by-trial basis by presenting CSs at volumes just above or below the perceptual detection threshold (see Method). Participants were expected to demonstrate differential UCS expectancies on perceived trials only. Prior research indicates that learning-related changes in SCR should develop on both perceived and unperceived delay conditioning trials (Knight et al., 2003). Similar findings for trace conditioning would indicate that awareness is also unnecessary for trace procedures. However, if awareness is necessary, differential SCRs should be demonstrated only during perceived trace CS presentations.

\section{METHOD}

\section{Participants}

Twenty-six volunteers ( 13 women, 13 men; mean age, $30.77 \pm 1.78$ years; range, 21-61 years) gave informed consent and participated in this study, which was conducted under a protocol approved by the National Institute of Mental Health Institutional Review Board. Participants were assigned to one of two groups. The first group (delay) consisted of 13 individuals ( 6 women, 7 men; mean age, $30.23 \pm 1.89$ years; range, $22-42$ years) who were exposed to a differential delay conditioning procedure. The second group (trace) consisted of 13 individuals ( 7 women, 6 men; mean age, $31.31 \pm 3.11$ years; range, 21-61 years) who were exposed to a differential trace conditioning procedure.

\section{Conditioned and Unconditioned Stimuli}

Two pure tones (700 and $1300 \mathrm{~Hz}$ ) were presented as CSs during the training session. The tones serving as CSs were counterbalanced and presented in a pseudorandom order such that no more than 2 trials of the same CS were consecutively presented. For the delay group, the $\mathrm{CS}+(10-\mathrm{sec}$ duration) coterminated with a $500-\mathrm{msec}$ loud (100-dB) white noise UCS and the CS - (10-sec duration) was presented alone. For the trace group, the CS+ (5-sec duration) was separated by a trace interval (4.5-sec duration) from a $500-\mathrm{msec}$ loud (100-dB) white noise UCS and the CS - (5-sec duration) was presented alone (see Figure 2). Participants received 60 conditioning trials $(30 \mathrm{CS}+$ and $30 \mathrm{CS}-$ ) presented at perithreshold volumes. CS volumes were modulated on a trial-by-trial basis using an adaptive threshold estimation procedure (Kaernbach, 2001; Treutwein, 1995)

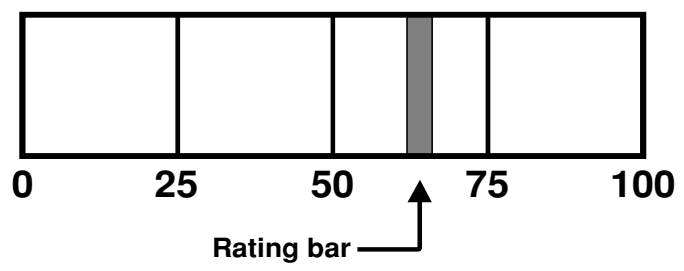

Figure 1. UCS expectancy rating bar. Participants were instructed to rate their UCS expectancy on a continuous scale from 0 to $100(0=$ certain that the UCS will not be presented, $50=$ uncertain whether the $U C S$ will be presented, $100=$ certain that the UCS will be presented) and were directed to continuously update their ratings to reflect their current UCS expectancy. such that CSs were perceived on some trials, but not on others (see Procedure).

\section{UCS Expectancy}

A computer mouse was used to monitor participants' perception of CSs and expectancy of receiving the UCS. CS perception was monitored by instructing participants to push the left mouse button immediately upon hearing either tone. In addition, the mouse controlled a rating bar presented throughout training on the computer monitor (see Figure 1). Participants were instructed to rate their UCS expectancy on a continuous scale from 0 to $100(0=$ certain that the UCS will not be presented, $50=$ uncertain whether the UCS will be presented, $100=$ certain that the UCS will be presented) and were instructed to continuously update (sampled at $40 \mathrm{~Hz}$ ) their rating to reflect their current UCS expectancy.

\section{Skin Conductance Response}

A Contact Precision Instruments (Cambridge, MA) skin conductance monitoring system was used to monitor skin conductance response (SCR) throughout the assessment. SCR was sampled $(40 \mathrm{~Hz})$ with a pair of surface gel cup electrodes $(\mathrm{Ag} / \mathrm{AgCl}, 6 \mathrm{~mm}$ diameter; BIOPAC [Goleta, CA] Model TSD203) attached to the distal phalanx of the middle and ring fingers of the nondominant hand.

\section{Procedure}

Participants were informed that two tones would be presented multiple times during the session and told that the volume of the tones would vary above and below their perceptual threshold. They were instructed to push the left mouse button immediately upon hearing a tone, and to update their UCS expectancy accordingly. Unknown to the participants, the volume of each CS (CS + and CSvolumes were modulated independently) was controlled by their buttonpress responses, in such a way that the volume of the CS was decreased by $3 \mathrm{~dB}$ following perceived trials (i.e., when a buttonpress was made) and was increased by $3 \mathrm{~dB}$ following unperceived trials (i.e., when a buttonpress was not made).

\section{Data Analysis}

UCS expectancy was calculated as the average (1-sec sample) response beginning $0.5 \mathrm{sec}$ prior to UCS presentation on CS + trials and the equivalent period of time on CS - trials. SCRs were also monitored during the conditioning session. SCR data were normalized (Lykken \& Venables, 1971), and response amplitude was calculated as a percentage of baseline responding by subtracting the average skin conductance measurement during the baseline period ( $5 \mathrm{sec}$ immediately preceding CS presentation) from the second interval response (peak response during the $5 \mathrm{sec}$ preceding UCS presentation on $\mathrm{CS}+$ trials and the equivalent period of time on $\mathrm{CS}$ - trials). The second interval response is generally considered an emotional response, elicited by UCS anticipation, that reflects learning the CS-UCS association (Boucsein, 1992; Prokasy \& Kumpfer, 1973; Wolter \& Lachnit, 1993). Paired $t$ test comparisons of UCS expectancy and SCR data for CS + versus CS - presentations were completed for perceived and unperceived trials.

\section{RESULTS}

CS perception was indexed by the buttonpress responses made by participants. Similar numbers of perceived (all values reflect the mean $\pm S E M$ : delay, CS $+15.62 \pm 0.56, \mathrm{CS}-$ $15.08 \pm 0.57$; trace, $C S+15.08 \pm 0.57, \mathrm{CS}-15.00 \pm 0.57)$ and unperceived (delay, CS $+14.31 \pm 0.55, \mathrm{CS}-$ $14.85 \pm 0.56$; trace, CS $+14.92 \pm 0.57, \mathrm{CS}-15.00 \pm 0.57)$ trials were presented over the conditioning session $[t(12)<$ $1.00]$. The volume of perceived CS presentations was greater than that of unperceived CSs $[t(24)=20.58, p<$ 


\section{Delay Conditioning}
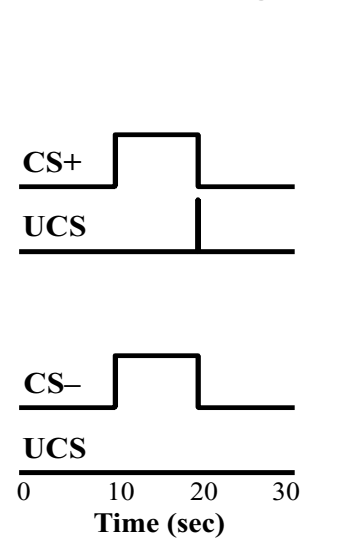

\section{Trace} Conditioning

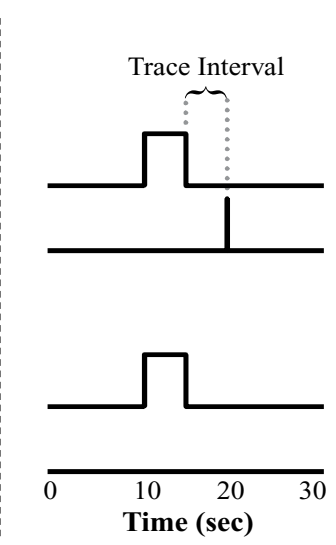

Figure 2. Differential delay and trace fear conditioning procedures. Delay conditioning included $30 \mathrm{CS}+$ trials that consisted of a 10-sec tone that coterminated with a 500-msec loud (100-dB) white noise UCS and $30 \mathrm{CS}-$ presentations of a different 10-sec tone presented alone. Trace conditioning consisted of $30 \mathrm{CS}+$ trials of a 5-sec tone that was separated from the UCS by a 4.5-sec trace interval and $30 \mathrm{CS}-$ presentations of a different 5-sec tone presented alone.

.05]. During delay conditioning, CS presentations were perceived at a lower threshold than during the trace procedure $[t(12)=2.39, p<.05]$. CS volumes were similar for $\mathrm{CS}+$ and $\mathrm{CS}-$ trials during both delay (perceived, CS + 49.34 $\pm 0.96, \mathrm{CS}-49.03 \pm 0.95 \mathrm{~dB}$; unperceived, CS+ $46.06 \pm 1.13, \mathrm{CS}-45.82 \pm 1.13 \mathrm{~dB})[t(12)<1.00]$ and trace (perceived, CS $+52.31 \pm 1.04, \mathrm{CS}-52.32 \pm 1.15 \mathrm{~dB}$; unperceived, CS $+49.15 \pm 0.82, \mathrm{CS}-48.87 \pm 1.05 \mathrm{~dB}$ ) $[t(12)<1.00]$ conditioning.

UCS expectancy and SCR to CS+ and CS - presentations were separated into perceived and unperceived trial types for statistical analysis. On perceived delay condi- tioning trials, participants demonstrated an awareness of CS-UCS contingencies with greater UCS expectancy during $\mathrm{CS}+(66.83 \pm 4.32)$ than during $\mathrm{CS}-(50.04 \pm 4.74)$ presentations $[t(12)=2.93, p<.05$; see Figure $3 \mathrm{~A}]$. UCS expectancy did not differ between the CS + $(58.49 \pm 4.21)$ and $\mathrm{CS}-(53.23 \pm 4.01)$ on unperceived trials $[t(12)=$ 1.68; see Figure 3B]. Learning-related changes in SCR were expressed during delay conditioning to both perceived and unperceived CSs (see Figures $3 \mathrm{C}$ and 3D). On perceived trials, SCRs evoked by the CS $+(2.32 \pm 0.60)$ were greater than those elicited by the CS $-(1.12 \pm 0.22)$ presentations $[t(12)=2.04, p<.05]$. Similar learningrelated responses were observed on unperceived trials such that the SCRs elicited by unperceived CS $+(1.67 \pm 0.38)$ presentations were larger than those produced on CS $(0.98 \pm 0.23)$ trials $[t(12)=1.86, p<.05]$.

During trace conditioning, participants also demonstrated an awareness of the CS-UCS contingencies on perceived trials. UCS expectancy was larger during perceived CS+ (77.02 \pm 2.17$)$ than during perceived $\mathrm{CS}-(62.40 \pm 3.96)$ presentations $[t(12)=2.87, p<.05$; see Figure 3E]. In contrast, UCS expectancy responses indicate that participants were unable to differentiate the CS $+(58.05 \pm 2.54)$ and $C S-(54.78 \pm 2.97)$ on unperceived trials $[t(12)=1.72$; see Figure $3 \mathrm{~F}]$. As in delay conditioning, learning-related changes in SCR were observed on perceived trace conditioning trials. Perceived CS $+(2.89 \pm 0.59)$ presentations elicited larger SCRs than those evoked by perceived CS$(1.96 \pm 0.50)$ presentations $[t(12)=2.41, p<.05$; see Figure $3 \mathrm{G}]$. However, unlike in delay conditioning, differential SCRs were not expressed during the $C S+(1.15 \pm 0.40)$ and $\mathrm{CS}-(0.79 \pm 0.28)$ on unperceived trace conditioning trials $[t(12)<1.00$; see Figure $3 \mathrm{H}]$.

\section{DISCUSSION}

The present study explored the role of awareness in the expression of conditional fear by concurrently measuring
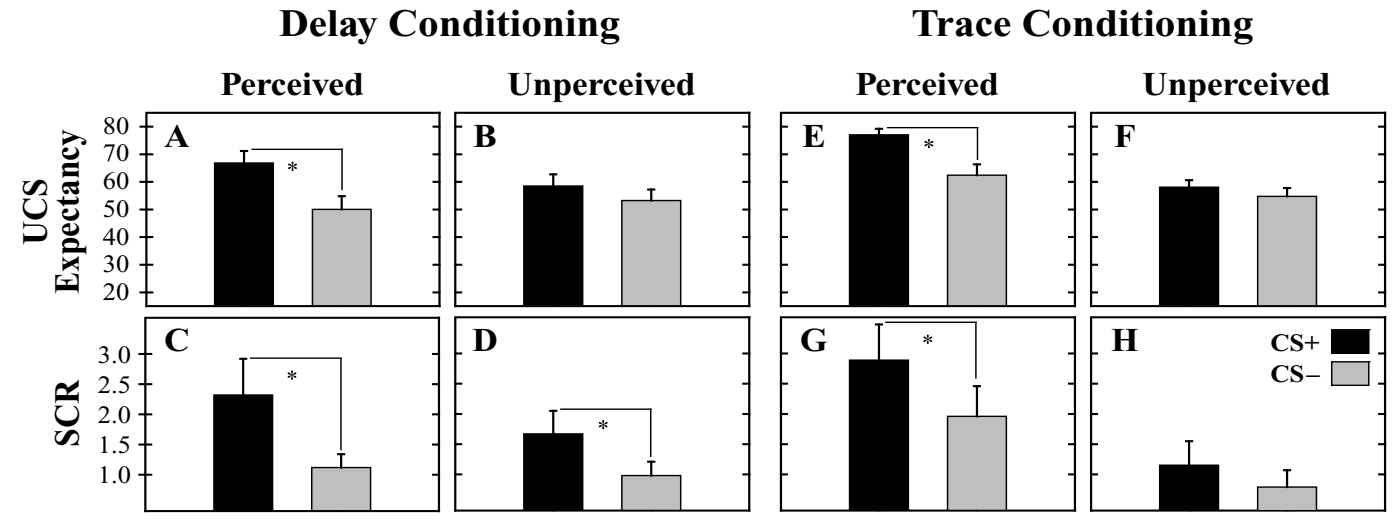

Figure 3. UCS expectancy and SCR data for perceived and unperceived delay and trace conditioning trials. Awareness was demonstrated on perceived delay (A) and trace (E), but not on unperceived delay (B) and trace (F) conditioning trials. During delay conditioning, differential SCRs were observed on both perceived (C) and unperceived (D) trials. During trace conditioning, learning-related changes in SCR were observed on perceived $(G)$, but not on unperceived $(H)$, trials. The asterisk indicates significant learning at $p<.05$. 
SCR and UCS expectancy as participants were exposed to a differential delay or trace fear conditioning procedure. The ability of participants to predict the UCS was varied on a trial-by-trial basis by presenting CSs at perithreshold volumes. Differential UCS expectancy was demonstrated on perceived, but not unperceived, delay and trace conditioning trials. Learning-related changes in SCR were observed during both perceived and unperceived delay CS presentations, which replicates prior work done with this methodology (Knight et al., 2003) and is consistent with the view that conditioning can develop without awareness (Clark \& Squire, 1998). In contrast, differential SCRs were observed only on perceived trace conditioning trials. These results suggest that awareness is necessary for CR expression during trace, but not delay, fear conditioning.

$\mathrm{CR}$ acquisition may rely on the simultaneous activation of neural pathways that transmit CS and UCS information. Therefore, the differential roles that awareness plays in delay and trace conditioning may be related to temporal differences in the CS-UCS relationship. During delay conditioning, the CS and UCS overlap. Consequently, the neuronal representation of the $\mathrm{CS}$ is active during UCS presentation. In contrast, the CS terminates prior to UCS onset during trace conditioning. As a result, the CS representation within the basic fear circuit may decay prior to UCS presentation, and higher level cognitive processes may be needed to maintain this representation and bridge the temporal gap between stimuli. Declarative memory may play a crucial role in forming a CS representation that can be maintained in working memory during the trace interval, and the interaction of these declarative and working memory processes may be necessary for the synaptic plasticity that mediates $\mathrm{CR}$ acquisition during trace conditioning (Clark, Manns, \& Squire, 2002; Clark \& Squire, 1998; Knight et al., 2004; Shors, 2004). Previous fear conditioning investigations suggest that there is significant overlap in the neural circuitry that supports delay and trace fear learning, although trace conditioning requires the recruitment of additional brain regions (Clark \& Squire, 1998; Knight et al., 2004; McEchron, Bouwmeester, Tseng, Weiss, \& Disterhoft, 1998; Moyer, Deyo, $\&$ Disterhoft, 1990). The amygdala appears to be a critical component of the neural circuit that mediates the expression of fear-related CRs (Cheng, Knight, Smith, Stein, \& Helmstetter, 2003; Davis, 2000; Knight, Nguyen, \& Bandettini, 2005; LeDoux, 2000; Maren, 2001), and auditory fear conditioning can be mediated independently through separate cortical and subcortical pathways to the amygdala (LeDoux, 2000). Subcortical projections from the auditory thalamus to the lateral amygdala appear to be sufficient to support delay fear conditioning (LeDoux, 2000). This pathway may provide circuitry for CS input to reach the amygdala and elicit fear responses without passing through cortical regions that mediate $\mathrm{CS}$ perception and awareness of CS-UCS relationships. In contrast, trace conditioning appears to require contributions from the cortical pathway and recruitment of hippocampal and prefrontal brain regions (Clark \& Squire, 1998; Knight et al., 2004;
Kronforst-Collins \& Disterhoft, 1998; Runyan, Moore, \& Dash, 2004). CS perception is likely mediated via thalamic projections to the auditory cortex (LeDoux, 2000; Näätänen \& Winkler, 1999), and declarative memory of stimulus relationships appears to rely on the hippocampus and medial temporal cortex (Milner et al., 1998). Furthermore, the declarative memory system of the medial temporal lobe may work in concert with prefrontal working memory regions to maintain the CS representation across the trace interval to support $\mathrm{CR}$ acquisition and expression (Büchel, Dolan, Armony, \& Friston, 1999; Clark \& Squire, 1998; Knight et al., 2004; Kronforst-Collins \& Disterhoft, 1998; Runyan et al., 2004).

The present results are consistent with prior evidence suggesting that awareness is necessary for CR expression during trace, but not delay, conditioning (Bechara et al., 1995; Clark et al., 2001; Clark \& Squire, 1998, 1999; Gabrieli et al., 1995; Knight et al., 2003; Manns et al., 2000; Smith et al., 2005). However, the present conclusions are based largely on the lack of statistical differences between the SCRs elicited by unperceived trace CS presentations. SCRs were slightly larger on unperceived trace CS + than on unperceived trace $\mathrm{CS}-$ trials, and perhaps significant differences would have been observed had it not been for other factors that can influence conditioning. For example, trace procedures appear to be more difficult than delay conditioning, and increasing task difficulty often interferes with CR acquisition (Carter et al., 2003; Solomon \& Groccia-Ellison, 1996; Thompson, Moyer, \& Disterhoft, 1996). In addition, the duration of the trace CS was shortened to maintain the same interstimulus interval between CS onset and UCS presentation for the delay and trace procedures. However, shorter duration CSs may be less salient, providing an alternative explanation for the lack of differential SCRs during unperceived trace CS presentations. Similarly, an important issue for future research to address is the influence of the trace interval duration on conditioning without awareness. In the present study, the UCS was presented $4.5 \mathrm{sec}$ after CS termination, and the basic fear circuit was presumably unable to maintain the CS representation across the trace interval on unperceived trials. If, however, the UCS followed a short-duration trace interval, it is possible that trace conditioning would be supported without awareness.

The impact of aging on fear learning is another important issue for conditioning research. Several studies have shown impaired conditioning with increasing age (Bellebaum \& Daum, 2004; Knuttinen, Power, Preston, \& Disterhoft, 2001; LaBar, Cook, Torpey, \& Welsh-Bohmer, 2004; Solomon, Pomerleau, Bennett, James, \& Morse, 1989; Woodruff-Pak \& Thompson, 1988). In the present study, the age (61 years) of one member of the trace group fell in a range that has previously shown impairment relative to younger subjects (Bellebaum \& Daum, 2004; LaBar et al., 2004). This participant's behavior (SCR and UCS expectancy) fell within the range observed for others in the trace group whose ages spanned from 21 to 41 years. Furthermore, exclusion of this data did not alter the statistical results. However, previous 
findings clearly show that age can have a significant impact on awareness and CR acquisition (Bellebaum \& Daum, 2004; Knuttinen et al., 2001; LaBar et al., 2004; Solomon et al., 1989; Woodruff-Pak \& Thompson, 1988).

Prior work investigating the role of awareness in differential fear conditioning to subliminal stimuli suggests that CRs are preferentially elicited by fear-relevant CSs (Öhman \& Mineka, 2001). Specifically, participants appear to have a greater predisposition to fear conditioning manipulations using visual stimuli such as snakes and spiders than they do to fear conditioning using images of flowers and mushrooms. Although fear-relevant CS-UCS associations may have an evolutionary advantage, conditioned associations to fear-irrelevant cues are not precluded (Öhman \& Mineka, 2001). In the present study, CR expression was observed to unperceived auditory (pure tones) CSs, confirming that stimulus associations with fear-irrelevant CSs can be formed. Future studies will need to determine whether the evolutionary predisposition observed for fear-relevant visual stimuli is also found within the auditory domain.

In conclusion, the present study investigated the role of awareness during Pavlovian fear conditioning, and the results suggest that awareness is necessary for CR expression in trace, but not delay, procedures. These findings reflect the independence of declarative and nondeclarative memory systems while demonstrating the critical role that awareness plays in more complex conditioning procedures. Although much remains unknown about the neural mechanisms mediating these cognitive-emotional interactions, functional MRI research from our laboratory is currently assessing brain activity associated with the aware and unaware expression of fear. This line of study may provide a better understanding of the independence, overlap, and interaction of the neural circuits mediating these declarative and nondeclarative memory processes.

\section{REFERENCES}

Bechara, A., Tranel, D., Damasio, H., Adolphs, R., Rockland, C., \& Damasio, A. R. (1995). Double dissociation of conditioning and declarative knowledge relative to the amygdala and hippocampus in humans. Science, 269, 1115-1118.

Bellebaum, C., \& Daum, I. (2004). Effects of age and awareness on eyeblink conditional discrimination learning. Behavioral Neuroscience, 118, 1157-1165.

Boucsein, W. (1992). Electrodermal activity. New York: Plenum.

Büchel, C., Dolan, R. J., Armony, J. L., \& Friston, K. J. (1999). Amygdala-hippocampal involvement in human aversive trace conditioning revealed through event-related functional magnetic resonance imaging. Journal of Neuroscience, 19, 10869-10876.

Carter, R. M., Hofstötter, C., Tsuchiya, N., \& Koch, C. (2003). Working memory and fear conditioning. Proceedings of the National Academy of Sciences, 100, 1399-1404.

Cheng, D. T., Knight, D. C., Smith, C. N., Stein, E. A., \& HelmstetTER, F. J. (2003). Functional MRI of human amygdala activity during Pavlovian fear conditioning: Stimulus processing versus response expression. Behavioral Neuroscience, 117, 3-10.

Clark, R. E., Manns, J. R., \& SQuire, L. R. (2001). Trace and delay eyeblink conditioning: Contrasting phenomena of declarative and nondeclarative memory. Psychological Science, 12, 304-308.

Clark, R. E., Manns, J. R., \& SQuire, L. R. (2002). Classical conditioning, awareness, and brain systems. Trends in Cognitive Sciences, 6, 524-531.
Clark, R. E., \& Squire, L. R. (1998). Classical conditioning and brain systems: The role of awareness. Science, 280, 77-81.

Clark, R. E., \& Squire, L. R. (1999). Human eyeblink classical conditioning: Effects of manipulating awareness of the stimulus contingencies. Psychological Science, 10, 14-18.

DAVIS, M. (2000). The role of the amygdala in conditioned and unconditioned fear and anxiety. In J. P. Aggleton (Ed.), The amygdala: A functional analysis (pp. 213-288). Oxford: Oxford University Press.

Esteves, F., Parra, C., Dimberg, U., \& Öhman, A. (1994). Nonconscious associative learning: Pavlovian conditioning of skin conductance responses to masked fear-relevant facial stimuli. Psychophysiology, 31, 375-385.

Gabrieli, J. D. E., McGlinchey-Berroth, R., Carrillo, M. C., Gluck, M. A., Cermak, L. S., \& Disterhoft, J. F. (1995). Intact delay-eyeblink classical conditioning in amnesia. Behavioral Neuroscience, 109, 819-827.

KaERnBaCH, C. (2001). Adaptive threshold estimation with unforcedchoice tasks. Perception \& Psychophysics, 63, 1377-1388.

Knight, D. C., Cheng, D. T., Smith, C. N., Stein, E. A., \& HelmstetTER, F. J. (2004). Neural substrates mediating human delay and trace fear conditioning. Journal of Neuroscience, 24, 218-228.

Knight, D. C., Nguyen, H. T., \& Bandettini, P. A. (2003). Expression of conditional fear with and without awareness. Proceedings of the National Academy of Sciences, 100, 15280-15283.

Knight, D. C., NGuyen, H. T., \& Bandettini, P. A. (2005). The role of the human amygdala in the production of conditioned fear responses. NeuroImage, 26, 1193-1200.

Knuttinen, M.-G., Power, J. M., Preston, A. R., \& Disterhoft, J. F. (2001). Awareness in classical differential eyeblink conditioning in young and aging humans. Behavioral Neuroscience, 115, 747-757.

Kronforst-Collins, M. A., \& Disterhoft, J. F. (1998). Lesions of the caudal area of rabbit medial prefrontal cortex impair trace eyeblink conditioning. Neurobiology of Learning \& Memory, 69, 147-162.

laBar, K. S., Cook, C. A., Torpey, D. C., \& Welsh-Bohmer, K. A. (2004). Impact of healthy aging on awareness and fear conditioning. Behavioral Neuroscience, 118, 905-915.

LeDoux, J. E. (2000). Emotion circuits in the brain. Annual Review of Neuroscience, 23, 155-184.

LyKKen, D. T., \& Venables, P. H. (1971). Direct measurement of skin conductance: A proposal for standardization. Psychophysiology, 8 , 656-672.

Manns, J. R., Clark, R. E., \& Squire, L. R. (2000). Parallel acquisition of awareness and trace eyeblink classical conditioning. Learning \& Memory, 7, 267-272.

Maren, S. (2001). Neurobiology of Pavlovian fear conditioning. Annual Review of Neuroscience, 24, 897-931.

McEchron, M. D., Bouwmeester, H., Tseng, W., Weiss, C., \& DisTERHOFT, J. F. (1998). Hippocampectomy disrupts auditory trace fear conditioning and contextual fear conditioning in the rat. Hippocampus, 8, 638-646.

Milner, B., SQuire, L. R., \& Kandel, E. R. (1998). Cognitive neuroscience and the study of memory. Neuron, 20, 445-468.

Moyer, J. R., Deyo, R. A., \& Disterhoft, J. F. (1990). Hippocampectomy disrupts trace eye-blink conditioning in rabbits. Behavioral Neuroscience, 104, 243-252.

NÄÄTÄNEN, R., \& WINKLER, I. (1999). The concept of auditory stimulus representation in cognitive neuroscience. Psychological Bulletin, 125, 826-859.

Öhman, A., \& MineKa, S. (2001). Fears, phobias, and preparedness: Toward an evolved module of fear and fear learning. Psychological Review, 108, 483-522.

Prokasy, W. F., \& Kumpfer, K. L. (1973). Classical conditioning. In W. F. Prokasy \& D. C. Raskin (Eds.), Electrodermal activity in psychological research (pp. 157-202). New York: Academic Press.

Runyan, J. D., Moore, A. N., \& Dash, P. K. (2004). A role for prefrontal cortex in memory storage for trace fear conditioning. Journal of Neuroscience, 24, 1288-1295.

Shors, T. J. (2004). Memory traces of trace memories: Neurogenesis, synaptogenesis and awareness. Trends in Neurosciences, 27, 250-256.

Smith, C. N., Clark, R. E., Manns, J. R., \& Squire, L. R. (2005). Acquisition of differential delay eyeblink classical conditioning is independent of awareness. Behavioral Neuroscience, 119, 78-86. 
Solomon, P. R., \& Groccia-Ellison, M. (1996). Classic conditioning in aged rabbits: Delay, trace, and long-delay conditioning. Behavioral Neuroscience, 110, 427-435.

Solomon, P. R., Pomerleau, D., Bennett, L., James, J., \& Morse, D. L. (1989). Acquisition of the classically conditioned eyeblink response in humans over the life span. Psychology \& Aging, 4, 34-41.

SQUIRE, L. R. (1992). Declarative and nondeclarative memory: Multiple brain systems supporting learning and memory. Journal of Cognitive Neuroscience, 4, 232-243.

Thompson, L. T., Moyer, J. R., \& Disterhoft, J. F. (1996). Trace eyeblink conditioning in rabbits demonstrates heterogeneity of learning ability both between and within age groups. Neurobiology of Aging, 17, 619-629.
Treutwein, B. (1995). Adaptive psychophysical procedures. Vision Research, 35, 2503-2522.

Wolter, J., \& Lachnit, H. (1993). Are anticipatory first and second interval skin conductance responses indicators of predicted aversiveness? Integrative Physiological \& Behavioral Science, 28, 163-166.

WoOdruff-PAK, D. S., \& Thompson, R. F. (1988). Classical conditioning of the eyeblink response in the delay paradigm in adults aged 18-83 years. Psychology \& Aging, 3, 219-229.

(Manuscript received May 20, 2005; revision accepted for publication October 24, 2005.) 